\author{
Politische Blockade
}

\title{
Beim Tabakwerbevorbot ist es fünf nach zwölf!
}

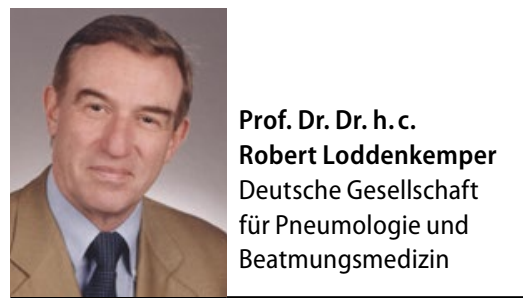

\author{
Seit fast einem Jahr liegt ein Gesetzesentwurf der Bundesregierung vor, der die Außenwerbung für \\ Zigaretten \& Co. verbieten soll. Im Bundestag wird er blockiert - ein gesundheitspolitischer Skandal.
}

_ Die Bundesregierung hat dem Bundestag einen Entwurf zur Änderung des Tabakerzeugnisgesetzes vorgelegt, mit dem die Werbung für Tabakerzeugnisse und auch für die besonders bei Kindern und Jugendlichen beliebter werdenden E-Zigaretten und EShishas weiter eingeschränkt werden soll. Insbesondere soll die AuBenwerbung verboten werden wenn auch erst 2020.

Das war im April 2016, und seitdem wartet die Öffentlichkeit darauf, dass der Entwurf im Bundestag gelesen und debattiert wird. Leider wird dies bislang von Teilen der CDU/CSU-Fraktion blockiert. Daran änderte sich auch nichts, als die Bundesminister für Gesundheit sowie für Ernährung und Landwirtschaft zusammen mit der Drogenbeauftragten der Bundesregierung - alle drei Mitglieder der Unionsfraktion - im Juni die Abgeordneten der Großen Koalition explizit um Unterstützung baten. Auch die Fraktionen von SPD, Grünen und Linken schlossen sich dem Appell an.

\section{Deutschland steht in der Pflicht}

In ihrem Schreiben weisen die drei Regierungsvertreter ausdrücklich darauf hin, dass Deutschland bereits vor 13 Jahren die Tabakrahmenkonvention FCTC der Weltgesundheitsorganisation unterzeichnet hat, und dass das nationale Umsetzungsgesetz bereits seit 10 Jahren in Kraft ist. Mittlerweile ist Deutschland

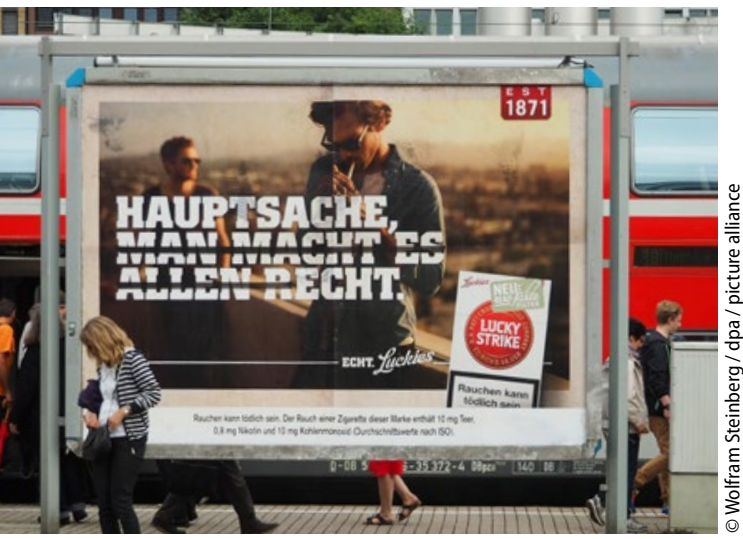

Plakat am S-Bahnhof: Die Werbebotschaften der Tabakindustrie verfangen vor allem bei Jugendlichen.

- so unglaublich das klingt - der einzige EU-Mitgliedsstaat, in dem die Plakataußenwerbung für Tabakerzeugnisse noch erlaubt ist.

In einer bislang einmaligen, von der Deutschen Gesellschaft für Pneumologie und Beatmungsmedizin koordinierten Aktion haben zudem mehr als 100 Medizinprofessoren aus den von den Folgen des Rauchens stark betroffenen Fachgebieten der Pneumologie, Kardiologie, Angiologie, Pädiatrie und Arbeitsund Umweltmedizin ihre Stimme erhoben. Im September richteten sie einen dringlichen Appell an die Abgeordneten, die Gesetzesvorlage auf die Tagesordnung des Bundestags zu setzen.

Gerade für sie als Ärzte, die täglich rauchbedingte Erkrankungen behandeln, sei es schwer erträglich, „dass die Politik angesichts des unendlichen Leids der Betroffenen immer noch zögert zu handeln“. Die Unterzeichner appellieren deshalb an die Verantwortung für den Schutz der Bevölkerung. Sie führen als wissenschaftlich unbestrittene Fakten an, dass Rauchen der wichtigste vermeidbare Risikofaktor für chronische, nicht übertragbare Krankheiten ist, an deren Folgen jährlich mehr als 120.000 Menschen in Deutschland frühzeitig sterben, und dass Rauchen bereits Kinder und Jugendliche tabakabhängig machen und zu einer lebenslangen Sucht führen kann. Dem Aufruf hat sich die Bundesärztekammer ebenso wie eine Reihe weiterer Organisationen angeschlossen.

\section{Die Bürger sind für das Verbot}

Nicht zuletzt befürworten nach einer aktuellen Umfrage vom Oktober 2016 auch drei Viertel der Bevölkerung ein Verbot der Außenwerbung. Die Zustimmung ist besonders hoch unter Nichtrauchern (87\%) und ehemaligen Rauchern (82\%), selbst von den Rauchern spricht sich die Hälfte (50,3\%) dafür aus.

Es bleibt also zu hoffen, dass der Bundestag das Gesetz noch in dieser Legislaturperiode verabschiedet. Deutschland geht innerhalb der EU oft mit gutem Beispiel voran. Warum ausgerechnet wir im Bereich der Tabakwerbung die rote Laterne tragen, ist den Bürgern nicht vermittelbar.

- Der Autor ist ehemaliger Präsident der Deutsche Gesellschaft für Pneumologie und Beatmungsmedizin (DGP) 